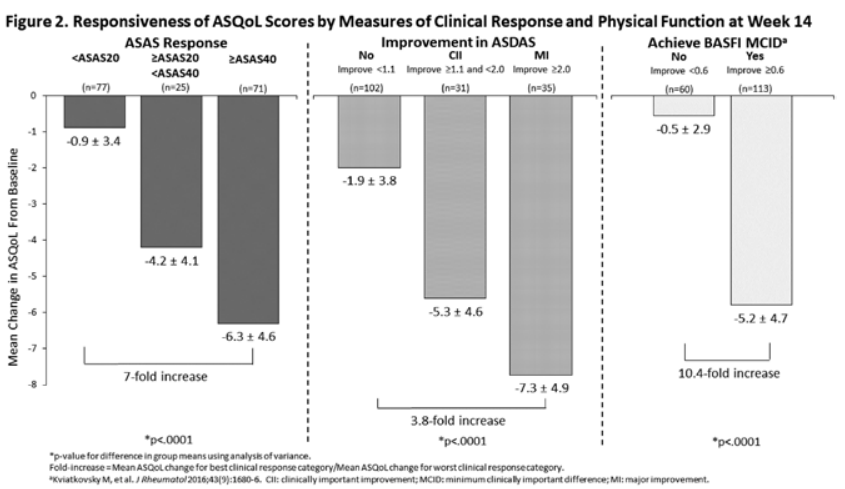

Acknowledgments: Financial support for the study was provided by AbbVie. AbbVie participated in interpretation of data, review, and approval of the abstract. All authors contributed to development of the abstract and maintained control over final content. Medical writing services, provided by Joann Hettasch of JK Associates Inc., were funded by AbbVie.

Disclosure of Interests: Uta Kiltz Grant/research support from: AbbVie, Amgen, Biogen, Novartis, Pfizer, Consultant of: AbbVie, Biocad, Eli Lilly and Company, Grünenthal, Janssen, Novartis, Pfizer, UCB, Speakers bureau: AbbVie, MSD, Novartis, Pfizer, Roche, UCB, Joachim Sieper Consultant of: AbbVie, Boehringer Ingelheim, Eli Lilly and Company, Janssen, Merck, Novartis, Pfizer, Roche, and UCB Pharma, Speakers bureau: AbbVie, Boehringer Ingelheim, Eli Lilly and Company, Janssen, Merck, Novartis, Pfizer, Roche, and UCB Pharma, Atul Deodhar Grant/research support from: AbbVie, Eli Lilly, GSK, Novartis, Pfizer, UCB, Consultant of: AbbVie, Amgen, Boehringer Ingelheim, Bristol Myer Squibb (BMS), Eli Lilly, GSK, Janssen, Novartis, Pfizer, UCB, Speakers bureau: AbbVie, Amgen, Boehringer Ingelheim, Bristol Myer Squibb (BMS), Eli Lilly, GSK, Janssen, Novartis, Pfizer, UCB, Patrick Zueger Shareholder of: AbbVie, Employee of: AbbVie, In-Ho Song Shareholder of: AbbVie Inc., Employee of: AbbVie Inc., Naijun Chen Shareholder of: AbbVie Inc, Employee of: AbbVie Inc, Désirée van der Heijde Consultant of: AbbVie, Amgen, Astellas, AstraZeneca, BMS, Boehringer Ingelheim, Celgene, Cyxone, Daiichi, Eisai, Eli-Lilly, Galapagos, Gilead Sciences, Inc., Glaxo-Smith-Kline, Janssen, Merck, Novartis, Pfizer, Regeneron, Roche, Sanofi, Takeda, UCB Pharma; Director of Imaging Rheumatology BV

DOI: 10.1136/annrheumdis-2020-eular.857

\section{THU0376 THE EFFECT OF 8 YEARS OF TNF-A BLOCKING THERAPY ON BONE MINERAL DENSITY IN PATIENTS WITH ANKYLOSING SPONDYLITIS}

M. Siderius $^{1,2}$, F. Wink ${ }^{1,2}$, A. Spoorenberg ${ }^{1,2}$, S. Arends ${ }^{1,2} .{ }^{1}$ University Medical Center Groningen, Rheumatology and Clinical Immunology, Groningen, Netherlands; ${ }^{2}$ Medical Center Leeuwarden, Rheumatology, Leeuwarden, Netherlands

Background: Ankylosing spondylitis (AS) is a chronic inflammatory disease that mainly affects the axial skeleton. Bone loss reflected by low bone mineral density (BMD) is a common feature of AS and can already be observed at early stages of the disease. A recent cohort study of 135 AS patients reported $7.2 \%$ improvement in lumbar spine BMD and 2.2\% improvement in hip BMD after 4 years of tumor necrosis factor-alpha (TNF-a) blocking therapy. ${ }^{1}$

Objectives: To assess the effect of 8 years of TNF-a blocking therapy on BMD of the lumbar spine and hip in AS patients.

Methods: Included in this study were consecutive AS outpatients from the Groningen-Leeuwarden Axial SpA (GLAS) cohort who received TNF-a blocking therapy for at least 8 years. A maximum of one switch to another TNF-a inhibitor was allowed. Patients were excluded when they used bisphosphonates at baseline or during follow-up. BMD of the lumbar spine (anterior-posterior projection L1-L4) (LS-BMD) and hip (total proximal femur) (hip-BMD) was measured at baseline, 1 year, 2 years and then bi-annually using dual-energy $\mathrm{X}$-ray absorptiometry (Hologic QDR Discovery (UMCG) or Hologic QDR Delphi (MCL), Waltman, MA, USA). Z-scores, the number of SD from the normal mean corrected for age and gender, were calculated using the NHANES reference database. Low BMD was defined as lumbar spine and/or hip BMD Z-score $\leq 1$. Generalized estimating equations were used to analyze BMD over time within subjects. Pairwise contrast were used to compare baseline and follow-up visits. P values $<0.05$ were considered statistically significant.

Results: In total, 131 AS patients were included; $73 \%$ were male, $83 \%$ HLAB27+, mean age was $41.3 \pm 10.8$ years, median symptom duration 14 years (IQR $7-24$ ), median CRP levels $13 \mathrm{mg} / \mathrm{L}$ (IQR 6-22), and $28 \%$ had poor vitamin $25(\mathrm{OH})$
D3 status $(<50)$ at baseline. $27 \%$ of patients switched to a second TNF-a inhibitor during follow-up and disease activity improved significantly during treatment: mean ASDAS ${ }_{\text {CRP }} 3.8 \pm 0.8$ at baseline and $2.1 \pm 0.9$ after 8 years $(P<0.001)$. At baseline, low BMD at the lumbar spine and hip was present in $34 \%$ and $19 \%$ patients, respectively. Both LS-BMD and hip BMD Z-scores were significantly improved during TNF-a blocking therapy at all follow-up visits compared to baseline. Significant improvement compared to the previous time point was found up to and including 4 years for the lumbar spine and up to and including 2 years for the hip. Thereafter, flattening of improvement was observed. Median percentage of improvement in absolute BMD after 8 years of TNF-a blocking therapy compared to baseline was 7.1\% (IQR 0.8-13.5) for the lumbar spine and $1.6 \%$ (IQR -3.5-5.5) for the hip (Figure 1).

Conclusion: In AS patients with established disease, both lumbar spine and hip BMD improved significantly at group level during 8 years of TNF- $a$ blocking therapy. This effect was most pronounced in the lumbar spine, which corresponds to the disease process in AS. Main improvements in lumbar spine BMD were observed during the first 4 years of treatment.

\section{References:}

[1] Beek et al. J Bone Miner Res. 2019; jun;34(6):1041-8
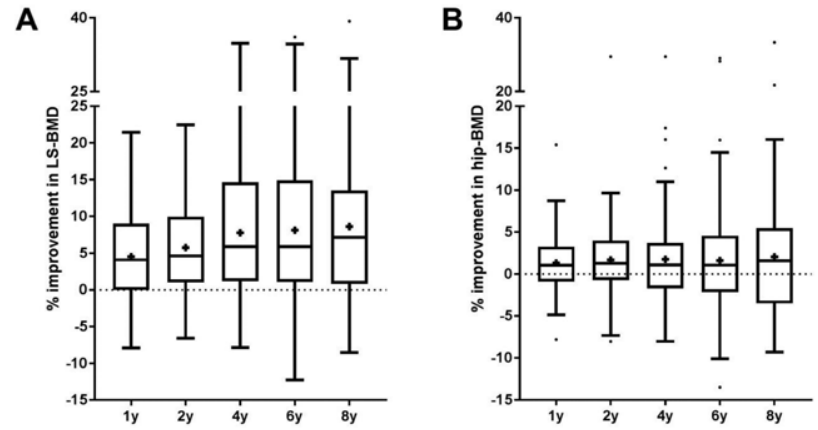

Figure 1. Percentage improvement during 8 years of TNF- $\alpha$ blocking therapy on LS-BMD (A) and hip-BMD (B) in patients with AS ( $n=131)$. Box-and-whisker plots (Tukey): boxes indicate medians with interquartile rar indicate outliers.

Disclosure of Interests: Mark Siderius: None declared, Freke Wink Consultant of: Abbvie, Janssen, Anneke Spoorenberg: None declared, Suzanne Arends Grant/research support from: Grant/research support from Pfizer DOI: 10.1136/annrheumdis-2020-eular.2189

\begin{tabular}{|l|l}
\hline THU0377 & IMPACT OF FILGOTINIB ON STRUCTURAL \\
& LESIONS IN THE SACROILIAC JOINTS AT 12 \\
& WEEKS IN PATIENTS WITH ACTIVE AXIAL \\
& SPONDYLOARTHRITIS: MAGNETIC RESONANCE \\
& IMAGING DATA FROM THE DOUBLE-BLIND, \\
& RANDOMIZED TORTUGA TRIAL
\end{tabular}

W. P. Maksymowych ${ }^{1}$, M. Ǿstergaard² ${ }^{2}$ R. B. M. Landewé ${ }^{3}$, W. Barchuk ${ }^{4}$, K. Liu ${ }^{4}$, C. Tasset ${ }^{5}$, L. Gilles ${ }^{6}$, T. Hendrikx ${ }^{7}$, R. Besuyen ${ }^{7}$, X. Baraliakos ${ }^{8} .{ }^{1}$ University of Alberta, Edmonton, Canada; ${ }^{2}$ Rigshospitalet, University of Copenhagen, Copenhagen, Denmark; ${ }^{3}$ Maastricht University Medical Center, Maastricht, Netherlands; ${ }^{4}$ Gilead Sciences, Inc, Foster City, CA, United States of America; ${ }^{5}$ Galapagos NV, Mechelen, Belgium; ${ }^{6}$ LACO, contracted by Galapagos NV, Mechelen, Belgium; ${ }^{7}$ Galapagos BV, Leiden, Netherlands; ${ }^{8}$ Ruhr-University Bochum, Herne, Germany

Background: Filgotinib, an oral selective Janus kinase (JAK) 1 inhibitor, reduced disease activity and improved symptoms and inflammation of the sacroiliac joint (SIJ) and spine in patients with active axial ankylosing spondylitis ( $\mathrm{AxSpA}$ ) in the Phase 2 TORTUGA trial (NCT03117270). ${ }^{1}$ The effects of JAK inhibitors on structural lesions in active AxSpA are unknown and optimal methods for image analysis of structural disease progression are not established.

Objectives: The aim of this post hoc analysis was to evaluate the effects of filgotinib on magnetic resonance imaging (MRI) measures of structural changes in the SIJ in patients from the TORTUGA trial, as assessed by Spondyloarthritis Research Consortium of Canada (SPARCC) SIJ Structural Scores (SSS).

Methods: TORTUGA was a multicenter, double-blind, randomized trial of 116 patients with active AxSpA treated with filgotinib $200 \mathrm{mg}(\mathrm{n}=58)$ or placebo $(n=58)$ once daily for 12 weeks. MRI was conducted at baseline and Week 12 (or early discontinuation visit). MRIs were re-evaluated post hoc by two independent experts (blinded to time point and assigned treatment) to determine SPARCC SSS; inter-reader discrepancies were resolved by an independent adjudicator. Observed changes from baseline were evaluated using analysis of covariance 